\title{
Neurons Promote the Translocation of Peripheral Myelin Protein 22 into Myelin
}

\author{
Sangeeta Pareek, ${ }^{1}$ Lucia Notterpek, ${ }^{2}$ G. Jackson Snipes, ${ }^{1}$ Roland Naef, ${ }^{3}$ Wayne Sossin, ${ }^{1}$ Jacynthe Laliberté, ${ }^{1}$ \\ Sandra lacampo, ${ }^{1}$ Ueli Suter, ${ }^{3}$ Eric M. Shooter, ${ }^{2}$ and Richard A. Murphy ${ }^{1}$ \\ ${ }^{1}$ Montreal Neurological Institute and the Faculty of Medicine, McGill University, Montreal, Quebec H3A 2B4, Canada, \\ 2Department of Neurobiology, Stanford University School of Medicine, Stanford, California 94305, and 3/nstitute of Cell \\ Biology, Swiss Federal Institute of Technology, ETH-Hönggerberg, CH-8093 Zürich, Switzerland
}

\begin{abstract}
Schwann cells express low levels of myelin proteins in the absence of neurons. When Schwann cells and neurons are cultured together the production of myelin proteins is elevated, and myelin is formed. For peripheral myelin protein 22 (PMP22), the exact amount of protein produced is critical, because peripheral neuropathies result from its underexpression or overexpression. In this study we examined the effect of neurons on Schwann cell PMP22 production in culture and in peripheral nerve using metabolic labeling and pulse-chase studies as well as immunocytochemistry. Most of the newly synthesized PMP22 in Schwann cells is rapidly degraded in the endoplas-
\end{abstract}

mic reticulum. Only a small proportion of the total PMP22 acquires complex glycosylation and accumulates in the Golgi compartment. This material is translocated to the Schwann cell membrane in detectable amounts only when axonal contact and myelination occur. Myelination does not, however, alter the rapid turnover of PMP22 in Schwann cells. PMP22 may therefore be a unique myelin protein in that axonal contact promotes its insertion into the Schwann cell membrane and myelin without altering its rapid turnover rate within the cell.

Key words: Schwann cells; PMP22; glycosylation; turnover; Golgi; axonal contact
Peripheral myelin protein 22 (PMP22) is a component of compact peripheral nerve myelin that is produced by Schwann cells (SC) (Suter et al., 1993; Snipes and Suter, 1995). PMP22 appears to be essential for peripheral nerve function, as determined by genetic studies. Mutations in the mouse pmp22 gene have been found in Trembler $(T r)$ (Suter et al., 1992a) and Trembler-J $\left(\operatorname{Tr}^{J}\right)$ mice (Suter et al., 1992b), both of which have severely demyelinated peripheral nerves. Point mutations in the human PMP22 gene have also been identified in some Charcot-Marie-Tooth disease type 1A (CMT1A) families (Valentijn et al., 1992b; Roa et al., 1993a,b) and in the clinically more severe hypertrophic neuropathy Dejerine-Sottas syndrome (Roa et al., 1993c). However, in most CMT1A patients the PMP22 gene is duplicated (Matsunami et al., 1992; Patel et al., 1992; Timmerman et al., 1992; Valentijn et al., 1992a). Furthermore, a heterozygous deletion of the same chromosomal region that is duplicated in CMT1A families has been detected in patients with hereditary neuropathy with liability to pressure palsies (HNPP) (Chance et al., 1993, 1994).

A CMT1A transgenic rat model has been generated that over-

Received March 9, 1997; revised June 24, 1997; accepted Aug. 7, 1997.

This work was supported by Medical Research Council of Canada Program Grant MRC-PG11473 and the Canadian Network of Centers of Excellence on Neural Regeneration and Functional Recovery (R.A.M.), National Institutes of Health Grants NS01559 (G.J.S.) and NS04270 (E.M.S.), grants from the American Paralysis Association and the Muscular Dystrophy Association (E.M.S.), and the Swiss National Science Foundation (U.S.). S.P. was supported by a fellowship from the Canadian Network of Centers of Excellence on Neural Regeneration and Functional Recovery. L.N. was supported by fellowships from the Giannini Foundation, National Institutes of Health Grant NS09694, and National Multiple Sclerosis Society Grant FG 1120-A-1. We thank Drs. Bruce Trapp and Juan José Archelos for the $\mathrm{P} 0$ antibodies.

S.P. and L.N. contributed equally to this work.

Correspondence should be addressed to Dr. Eric M. Shooter, Department of Neurobiology, Stanford University School of Medicine, Stanford, CA 94305.

Copyright (C) 1997 Society for Neuroscience $0270-6474 / 97 / 177754-09 \$ 05.00 / 0$ expresses PMP22. These animals develop SC hypertrophy, muscle weakness, and reduced conduction velocities (Sereda et al., 1996) similar to CMT1A patients. Moreover, PMP22-deficient transgenic mice show delayed onset of myelination, tomacula-like focal myelin thickenings followed by severe demyelination, axonal loss, and functional impairment similar to what is seen in HNPP (Adlkofer et al., 1995). All these findings emphasize that the absolute level of PMP22 protein is of critical importance for correct myelin formation and maintenance and, in turn, focus on how the synthesis and targeting of PMP22 in SC in nerve is regulated.

Similar to PMP22, the expression level and proper processing of other myelin proteins is of critical importance for normal glial cell biology (Scherer and Chance, 1995). For example, heterozygous and homozygous deletions of the protein zero (P0) gene lead to demyelinating and dysmyelinating phenotypes, respectively (Martini et al., 1995). Furthermore, point mutations in P0 are associated with a heterogeneous group of dysmyelinating disorders (Warner et al., 1996). One possible mechanism for some of the observed differences in clinical phenotypes is that each specific mutation uniquely alters the trafficking of the mutated P0 protein. Recent studies in our laboratories show that there is a similar functional heterogeneity with respect to pmp22 mutations present in the $\operatorname{Tr}$ and $\operatorname{Tr}^{J}$ mice. In $\operatorname{Tr}$, PMP22 is retained in the endoplasmic reticulum (ER) (Naef et al., 1997), whereas in $\operatorname{Tr}^{J}$, PMP22 accumulates in lysosomal compartments of the Schwann cells (Notterpek et al., 1997).

As a step toward understanding the pathogenesis of the observed neuropathies, one must define the normal trafficking of the wild-type PMP22 protein. Like the other peripheral myelin proteins, PMP22 mRNA and protein synthesis is significantly upregulated in SC by axonal contact (Snipes et al., 1992; Bosse et al., 1994; Suter et al., 1994). In exploring this aspect of PMP22 
biology further, we have previously shown that, unlike the major myelin protein $\mathrm{P} 0, \mathrm{PMP} 22$ has a short half-life in SC in culture (Pareek et al., 1993). We now show that this characteristic feature of PMP22 synthesis does not change in SC that are in contact with axons in co-culture or in nerve. Moreover, unlike P0, PMP22 is only targeted to the SC membrane in detectable amounts when $\mathrm{SC}$ myelinate axons.

\section{MATERIALS AND METHODS}

Tissue culture. SC cultures were prepared from neonatal rat sciatic nerves according to the methods of Brockes et al. (1979) and modified as described previously (Pareek et al., 1993). SC were maintained in medium supplemented with $5 \mu \mathrm{M}$ forskolin to stimulate myelin-related gene expression (Lemke and Chao, 1988; Pareek et al., 1993).

Dissociated cultures of sensory neurons from Sprague Dawley rat embryos were established as described previously (Kleitman et al., 1991) Briefly, embryonic day 15 dorsal root ganglia (DRG) were enzymatically and mechanically dissociated. Cells were plated on $12 \mathrm{~mm}$ collagencoated glass coverslips for morphological studies or on collagen-coated tissue culture plastic for biochemical analysis. The day after the dissection, the cultures were treated with fluorodeoxyuridine $(10 \mu \mathrm{M})$ for at least three cycles to remove non-neuronal cells.

Co-cultures of DRG neurons and SC (DRG-SC) were established as described by Einheber et al. (1993). Briefly, SC were harvested by trypsin treatment $(0.05 \%$ containing $0.02 \%$ EDTA) and plated onto established DRG neurons. SC were allowed to proliferate and attach to neurons. Myelin synthesis was induced by incubating the cultures in medium containing $15 \%$ fetal calf serum, $50 \mu \mathrm{g} / \mathrm{ml}$ ascorbic acid, and $20 \mathrm{ng} / \mathrm{ml}$ progesterone (Koenig et al., 1995). Cultures were maintained for up to 3 months. Myelin production was confirmed by immunocytochemical and biochemical methods.

Immunocytochemistry. SC and co-cultures were fixed in $4.0 \%$ paraformaldehyde in PBS for $10 \mathrm{~min}$ at room temperature followed by postfixation and permeabilization in $100 \%$ methanol for $10 \mathrm{~min}$ at $-20^{\circ} \mathrm{C}$. Samples were blocked by incubation in $20 \%$ normal goat serum containing PBS for at least $30 \mathrm{~min}$ at room temperature. Primary antibodies were added in the same blocking solution for $2-3 \mathrm{hr}$ at room temperature or overnight at $4^{\circ} \mathrm{C}$ (co-cultures). A previously characterized rabbit polyclonal antibody (Corinne) raised against synthetic peptide of the rat PMP22 (amino acids 117-132) (Notterpek et al., 1997) was used at dilution of 1:250 for staining of the co-cultures. A second polyclonal anti-PMP22 antibody (Andy) raised against the corresponding human peptide was used for immunostaining of the SC. In this region, sequences of the rat and human PMP22 are $81 \%$ homologous, and antibodies to the two species cross-react. For double-immunolabeling studies, a mouse monoclonal antibody to P0 (a gift from Dr. J. J. Archelos, Bayerische Julius-Maximilians Universität, Wurzburg, Germany), antibody to neurofilament (NF) (Dako, Carpinteria, CA), and an antibody to $58 \mathrm{kDa}$ Golgi protein (Sigma, St. Louis, MO) were used. After three $10 \mathrm{~min}$ rinses in PBS, we added fluorochrome-conjugated secondary antibodies from goat, including FITC-conjugated anti-mouse IgG and IgM (Boehringer Mannheim, Indianapolis, IN), and Texas Red-conjugated antirabbit IgG (Jackson ImmunoResearch, West Grove, PA) for 1-2 hr at room temperature. Preimmune and peptide-adsorbed rabbit antisera were used as controls. Control samples without primary antibodies were processed in parallel. Coverslips were mounted with Citifluor (University of Kent, Canterbury, UK), and samples were photographed using a Nikon Microphot FXA microscope.

Metabolic labeling. Cells in culture and sciatic nerve explants were metabolically labeled with $0.4 \mathrm{mCi} / \mathrm{ml}$ trans ${ }^{-35} \mathrm{~S}$ label $(1100 \mathrm{Ci} / \mathrm{mmol}$; ICN Biochemicals, Costa Mesa, CA) as described (Pareek et al., 1993). For pulse-chase studies, cells were incubated in trans ${ }^{-35} \mathrm{~S}$ label containing medium for 30-45 min, washed twice with prewarmed DMEM, and incubated in fresh medium with an excess of cold methionine and cysteine for varying time intervals.

Immunoprecipitation. SC and DRG-SC co-cultures were solubilized on ice for $45 \mathrm{~min}$ in $1.5 \mathrm{ml}$ of precipitation buffer (50 mM Tris- $\mathrm{HCl}, \mathrm{pH} 8.0$, $150 \mathrm{~mm} \mathrm{NaCl}, 1 \%$ deoxycholate, $0.5 \%$ Nonidet P-40, and $0.1 \%$ SDS) containing $20 \mu \mathrm{g} / \mathrm{ml}$ aprotinin, $1 \mathrm{~mm}$ phenylmethylsulfonyl fluoride, and $20 \mu \mathrm{g} / \mathrm{ml}$ leupeptin. Cell lysates were immunoprecipitated with a previously characterized polyclonal antibody raised against rat PMP22 peptide (amino acids 117-132) (Pareek et al., 1993) or with antibodies to P0 (a gift from Dr. Bruce Trapp, Cleveland Clinic Foundation, Cleveland,
$\mathrm{OH}$ ) as described previously (Pareek et al., 1993). For endoglycosidase H (Endo $\mathrm{H})$ treatment, agarose beads containing complexes of radiolabeled antigen and antibody were resuspended in $200 \mu \mathrm{l}$ of $20 \mathrm{~mm}$ sodium phosphate, $\mathrm{pH} 6.0$, and $20 \mathrm{~mm} \mathrm{NaCl}$. For $N$-glycosidase F (PNGase F) treatment, agarose beads were resuspended in $200 \mu \mathrm{l}$ of $200 \mathrm{~mm}$ sodium phosphate buffer, $\mathrm{pH}$ 7.6, containing $0.1 \%$ SDS and $10 \mathrm{~mm} \beta$ mercaptoethanol. After $5 \mathrm{~min}$ incubation, a nonionic detergent Nonidet P-40 was added to a sevenfold excess over SDS, before the addition of PNGase F. One-half of each sample received Endo H (5 mU; Boehringer Mannheim) or PNGase F (1.25 U; Genzyme, Cambridge, MA), and the other half received buffer without enzyme. Samples were incubated for $16-18 \mathrm{hr}$ at 4 or $37^{\circ} \mathrm{C}$ for Endo $\mathrm{H}$ and at $37^{\circ} \mathrm{C}$ for PNGase $\mathrm{F}$ and then washed three times in (in mM) 2 EDTA, 0.5 dithiothreitol, and 10 Tris- $\mathrm{HCl}, \mathrm{pH} 7.5$, at $4^{\circ} \mathrm{C}$. The beads were resuspended in SDS sample buffer (in \%: 2 SDS, $5 \beta$-mercaptoethanol, 10 glycerol, and 0.001 bromophenol blue), boiled for $5 \mathrm{~min}$, and analyzed by SDS-PAGE using a 13-22\% gradient gel system. After electrophoresis, gels were fixed in $40 \%$ methanol and $10 \%$ acetic acid and treated with ENHANCE (DuPont NEN, Boston, MA) according to the manufacturer's instructions. Dried gels were exposed to Kodak XAR film and developed on an $\mathrm{X}$-Omat film processor. Densitometric analyses of the autoradiographs were performed using National Institutes of Health Image software. Identical methods were used to analyze homogenates of metabolically labeled sciatic nerve explants.

Western blot analysis. Purified rat myelin membranes were prepared from adult rat sciatic nerves by the method of DeVries et al. (1978). Endoglycosidase digestions, PNGase F and Endo H (both from New England Biolabs, Beverly, MA) were performed according to the manufacturer's suggestions. Sciatic nerve homogenates, purified myelin, lysates of DRG-SC co-cultures, and SC alone were prepared directly in the denaturation buffer supplied with the enzymes. Protein concentrations were determined by the method of Lowry et al. (1951). As a positive control for Endo H activity, $2 \mu \mathrm{g}$ of RNaseB (Sigma) was added to the SC lysates. Samples with and without enzyme were incubated for $16 \mathrm{hr}$ at $37^{\circ} \mathrm{C}$. Proteins were separated on $12.5 \%$ SDS gels under reducing conditions, and gels were transferred to nitrocellulose membranes (Towbin et al., 1979). After blocking with 5\% skim milk in PBS, blots were incubated with the same anti-rat PMP22 antiserum (Corinne; 1:1000) that was used for the co-culture immunocytochemical studies in $5 \%$ goat serum containing PBS for $16 \mathrm{hr}$ at $4^{\circ} \mathrm{C}$. Bound antibodies were detected using the ECL detection method (Amersham, Arlington Heights, IL). Cleavage of RNaseB by Endo $\mathrm{H}$ and PNGase $\mathrm{F}$ was monitored by Coomassie blue staining of parallel gels and by Ponceau S staining of the nitrocellulose membranes before Western blotting.

\section{RESULTS}

\section{Most newly synthesized PMP22 in cultured SC remains in the ER}

We have previously shown that PMP22 is expressed in SC in a glycosylated form that is generated from an $18 \mathrm{kDa}$ precursor, and that the turnover rate of PMP22 in these cells is rapid, with a half-life of 30-60 min (Pareek et al., 1993). To determine where within the cell the degradation of newly synthesized PMP22 occurs, we metabolically labeled SC, immunoprecipitated PMP22, and treated the precipitate with Endo H before electrophoresis (Fig. 1A). Endo $\mathrm{H}$ removes high mannose-containing, noncomplex sugar residues from newly synthesized proteins. Because glycoproteins become Endo $\mathrm{H}$ resistant only after cleavage by mannosidase II, which is located within the medial Golgi compartment (Kornfeld and Kornfeld, 1985), Endo H sensitive glycoproteins are thought to be located within the ER. Endo H resistant, complex carbohydrate-containing proteins are found in the Golgi compartment. Figure $1 A$ shows that most of the newly synthesized PMP22 is sensitive to Endo $\mathrm{H}$ treatment, indicating its location within the ER, and is rapidly degraded within 30-60 min. Only a few percent of the newly synthesized, labeled PMP22 remains after a $60 \mathrm{~min}$ chase (Fig. $1 A$ ). Most of this protein (78\%) has a slightly elevated molecular mass (Fig. $1 A$, right arrow) and is resistant to Endo $\mathrm{H}$.

To test whether our culture conditions were artificially promot- 


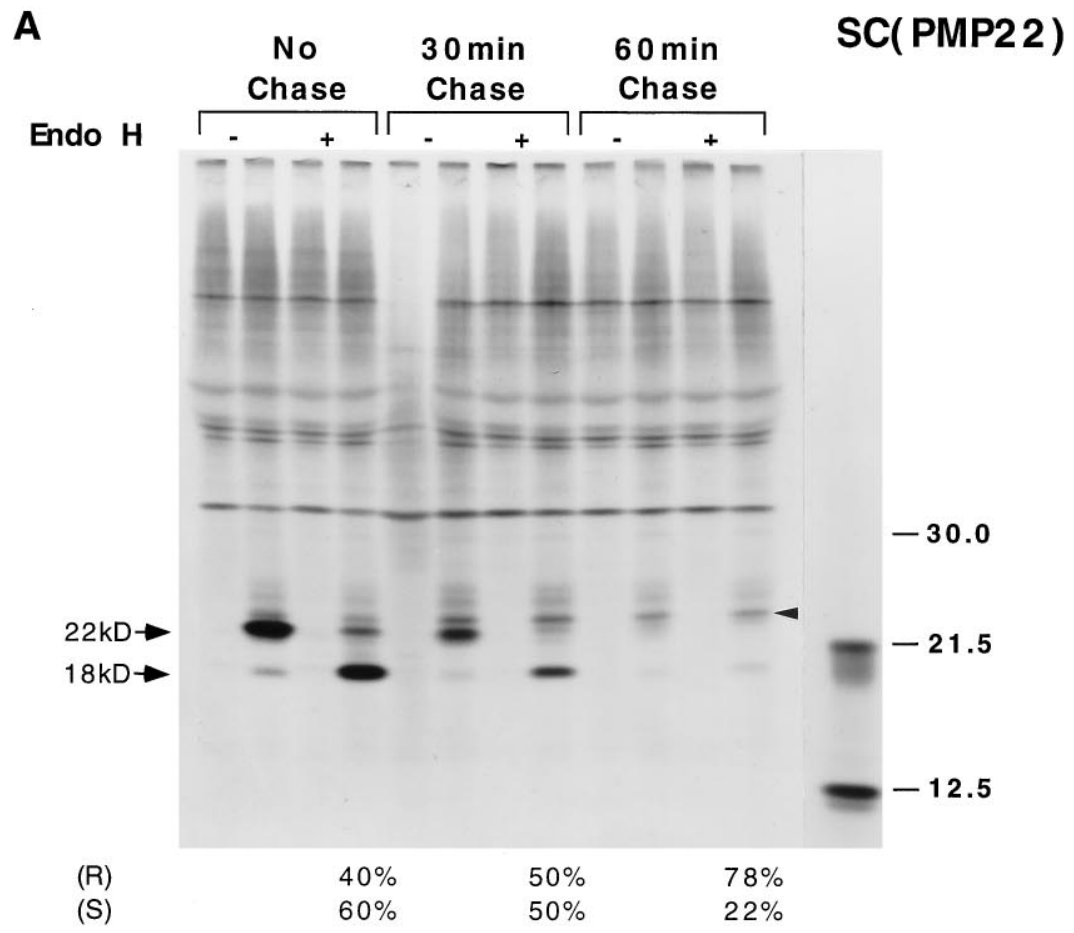

Figure 1. Pulse-chase analysis and Endo $\mathrm{H}$ digestion of PMP22 $(A)$ and $\mathrm{P} 0(B)$ in SC. SC were metabolically labeled with trans $-{ }^{35} \mathrm{~S}$ label for $30 \mathrm{~min}$ and chased for 30 and 60 min with cold methionine and cysteine. SC lysates were immunoprecipitated with either PMP22 $(A)$ or $\mathrm{P} 0(B)$ antibodies, and the immunoprecipitates were incubated with (+) or without (-) Endo $\mathrm{H}$ at $4^{\circ} \mathrm{C}$ for $16-18 \mathrm{hr}$. After immunoprecipitation, cell lysates were analyzed by SDSPAGE and fluorography. Duplicate samples were precipitated with preimmune serum ( first lane in each group). The migration positions of PMP22 and $\mathrm{P} 0$ are indicated by arrows. Top arrows show the glycosylated proteins, and bottom arrows show the unglycosylated proteins. The right arrow in $A$ shows the Endo H resistant PMP22. Molecular weight markers are shown at the extreme right in both $A$ and $B$. Endo $\mathrm{H}$ resistant $(R)$ and sensitive $(S) \mathrm{PMP} 22(A)$ and P0 $(B)$ are shown as the percentage of total protein at different time intervals.

ing the rapid disappearance of PMP22, we monitored in identical samples the turnover rate of $\mathrm{P} 0$, the major SC-derived glycoprotein of peripheral nerve myelin. In contrast to PMP22, almost all of the newly synthesized $\mathrm{P} 0$ remained after a 60 min chase period (Fig. $1 B$ ). Furthermore, within 30 min of chase, most of the newly synthesized P0 (87\%) was converted to an Endo $\mathrm{H}$ resistant form. Therefore, under these culture conditions, SC transfer P0 from the ER to the Golgi compartment and process the carbohydrate moiety of the protein.

\section{A complex glycosylated form of PMP22 accumulates over time}

Although it represents only a small fraction of the protein produced in SC, the Endo H resistant form of PMP22 accumulates
B

$\mathrm{SC}(\mathrm{PO})$

\section{(all
alo-
all
rm.
rom
rate

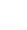

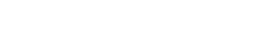

(n)

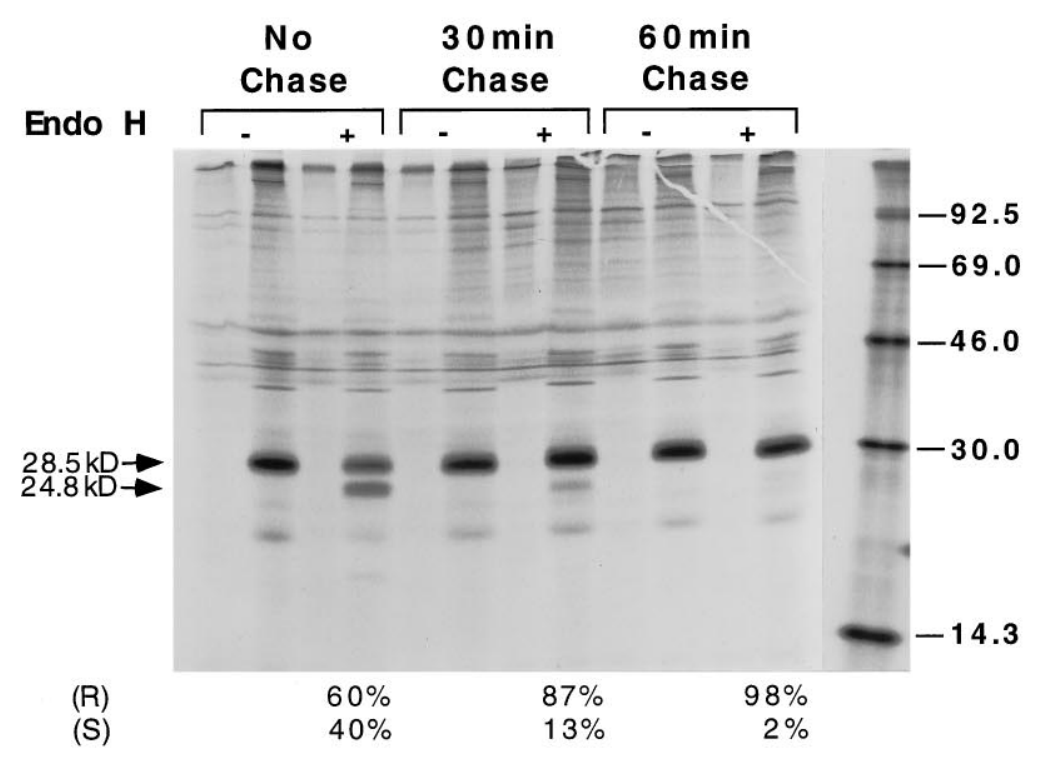

over time. Figure 2 compares SC cultures that were metabolically labeled either for a short (45 min) or long term (6 or $16 \mathrm{hr})$. After immunoprecipitation, the samples were incubated in the presence or absence of Endo H or PNGase F. In cells radiolabeled for 6 or $16 \mathrm{hr}$, the labeled PMP22 is more heterogeneous than PMP22 labeled for $45 \mathrm{~min}$ (Fig. 2, top arrow). That all these bands contribute to PMP22 was confirmed by digestion with PNGase F, which completely removes the carbohydrate moiety from PMP22. This digestion changed the molecular mass of all these bands downward by $\sim 4 \mathrm{kDa}$, the difference between the glycosylated and unglycosylated forms of PMP22 (Fig. 2, bottom arrow). Whereas $\sim 70 \%$ of the short-term-labeled (45 min) PMP22 is Endo $\mathrm{H}$ sensitive, only $\sim 20 \%$ of the long-term-labeled PMP22 is 
Schwann cells

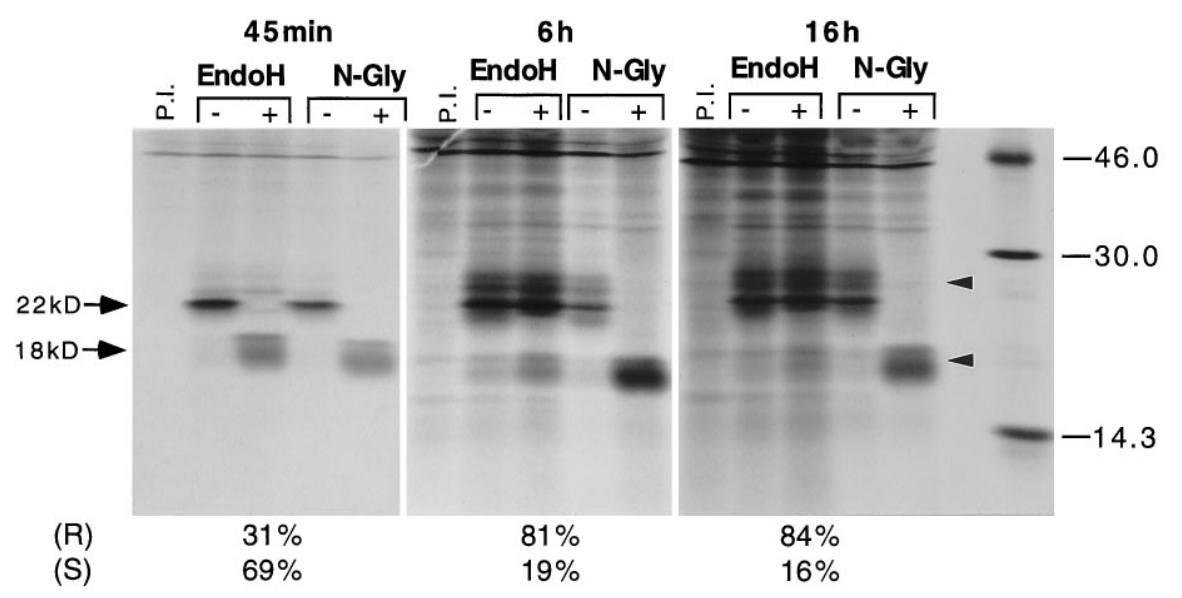

Figure 2. Comparison of short- and long-term labeling of cultured SC. SC were metabolically labeled with trans ${ }^{35} \mathrm{~S}$ label for $45 \mathrm{~min}, 6 \mathrm{hr}$, or 16 hr. Cell lysates were immunoprecipitated with PMP22 antibodies, and the immunoprecipitates were incubated with $(+)$ or without $(-)$ Endo $\mathrm{H}$ or PNGase F $(N-G l y)$ at $37^{\circ} \mathrm{C}$ for $16-18 \mathrm{hr}$. After immunoprecipitation, cell lysates were analyzed by SDS-PAGE and fluorography. Duplicate samples were treated with preimmune serum (first lane in each group). The migration positions of glycosylated $22 \mathrm{kDa}$ PMP22 (top arrow) and the 18 $\mathrm{kDa}$ core peptide (bottom arrow) are indicated. The top right arrow shows the Endo $\mathrm{H}$ resistant accumulated PMP22 protein, and the bottom right arrow shows the $18 \mathrm{kDa}$ core protein that appears after PNGase F digestion. Molecular weight markers are shown at the extreme right. Endo $\mathrm{H}$ resistant $(R)$ and sensitive $(S)$ PMP22 are shown as the percentage of total protein at different time intervals.
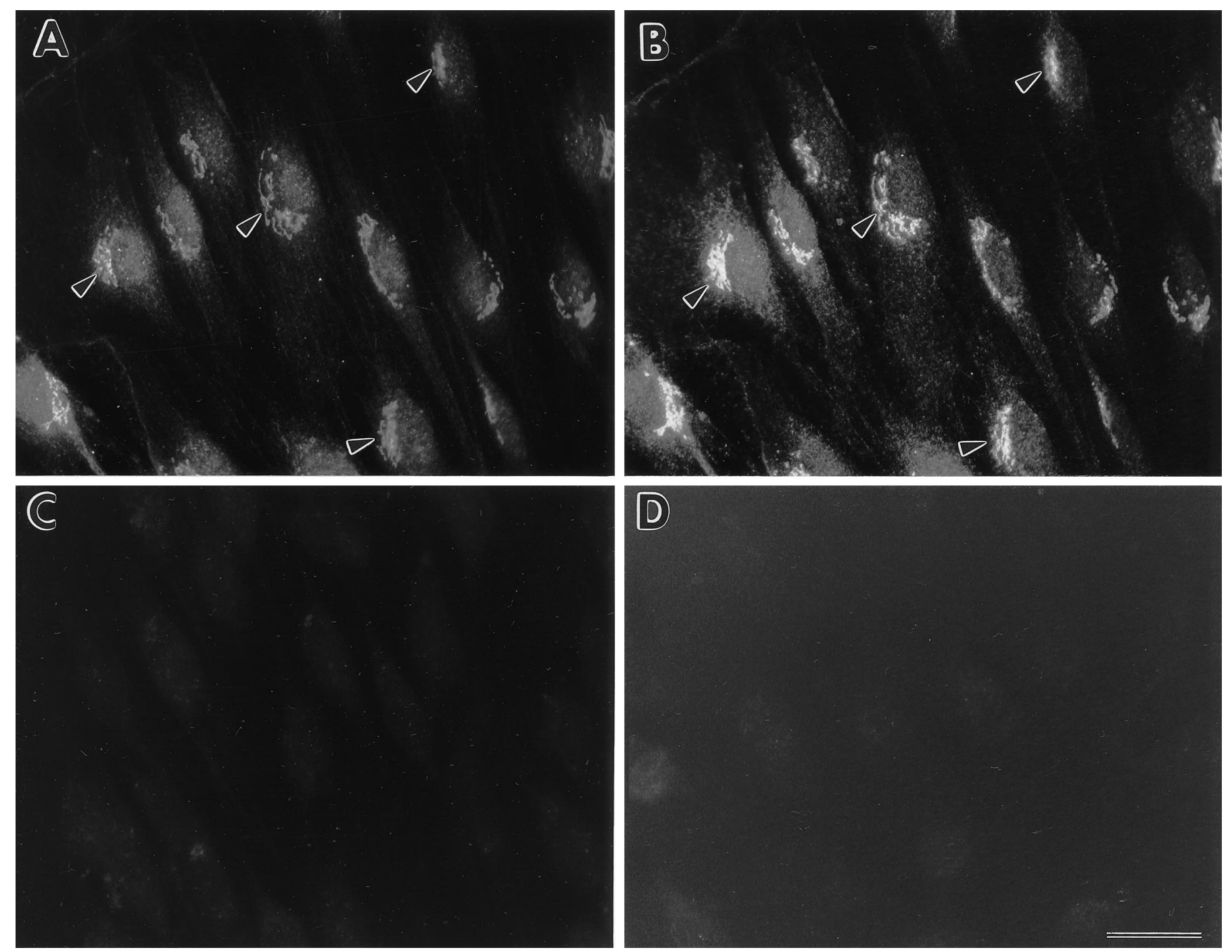

Figure 3. Immunocytochemical localization of PMP22 in cultured SC. SC cultures were fixed in $4.0 \%$ paraformaldehyde and permeabilized by treatment with methanol. Samples were double-stained with PMP22 antisera visualized by Texas Red-conjugated anti-rabbit IgG and monoclonal Golgi marker (FITC). The distribution of PMP22 $(B)$ and the $58 \mathrm{kDa}$ Golgi protein $(A)$ are shown. Most of the PMP22-like immunoreactivity co-localized with the Golgi marker (arrows in $A, B$ ). Controls are shown in which the samples were incubated with PMP22 peptide-adsorbed antiserum ( $C$ ) or preimmune serum $(D)$. Scale bar (shown in $D), 22 \mu \mathrm{m}$. 
A

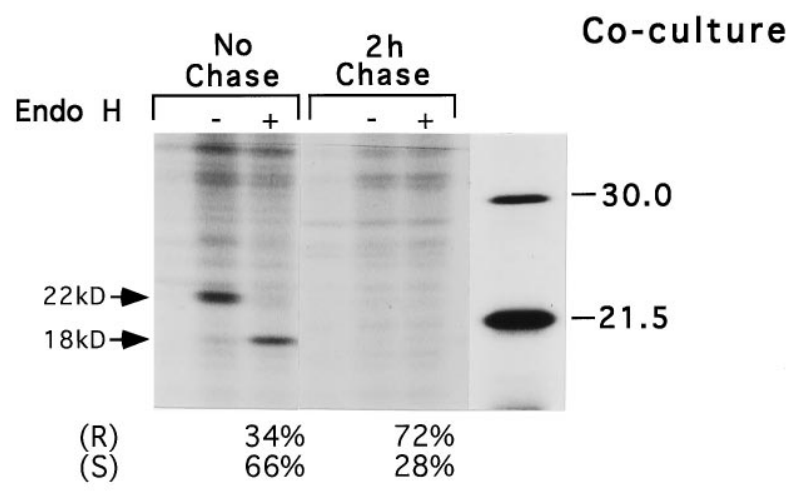

B

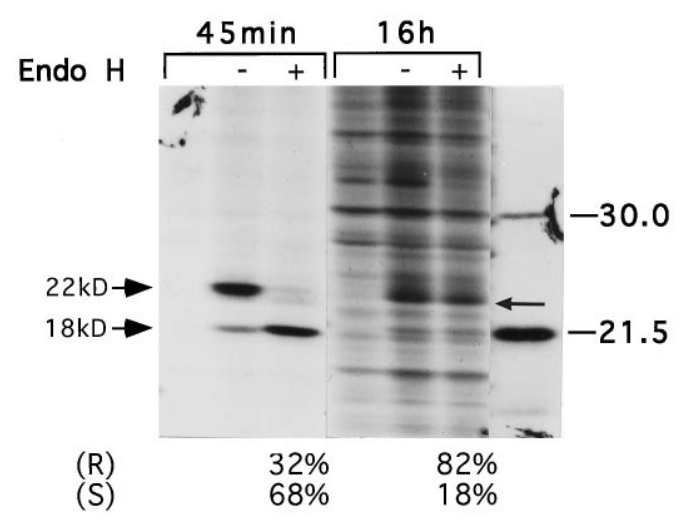

Figure 4. Pulse-chase analysis $(A)$ and short- and long-term labeling $(B)$ of PMP22 in myelinating co-cultures of SC and neurons. DRG-SC cocultures were grown in the presence of ascorbic acid and progesterone. Cells were metabolically labeled with trans ${ }^{-35} \mathrm{~S}$ label for $45 \mathrm{~min}$ and chased for $2 \mathrm{hr}$ with cold methionine and cysteine $(A)$. For comparison of short- and long-term labeling studies $(B)$, myelinating co-cultures were metabolically labeled with trans ${ }^{35}{ }^{35}$ label for either $45 \mathrm{~min}$ or $16 \mathrm{hr}$. Cell lysates were immunoprecipitated with PMP22 antibodies, and the immunoprecipitates were incubated with $(+)$ or without $(-)$ Endo $\mathrm{H}$ at $4^{\circ} \mathrm{C}$ for $16-18 \mathrm{hr}$. After immunoprecipitation, the lysates were analyzed by SDSPAGE and fluorography. Duplicate samples were precipitated with preimmune serum (first lane in each group). The migration positions of glycosylated PMP22 (top arrows) and the $18 \mathrm{kDa}$ core peptide (bottom arrows) are indicated. The right arrow in $B$ indicates the accumulated Endo H resistant PMP22 protein. Molecular weight markers are shown at the extreme right. Endo $\mathrm{H}$ resistant $(R)$ and sensitive $(S)$ PMP22 are shown as the percentage of total protein at different time intervals.

Endo H sensitive. Therefore, the PMP22 that accumulates within $\mathrm{SC}$ over time must be the small proportion of newly made stable, Endo $\mathrm{H}$ resistant protein.

\section{Stable PMP22 immunoreactivity is detectable within the Golgi compartment of SC}

Although the rapidly degraded PMP22 is located within the ER, most of the stable Endo H resistant PMP22 accumulates in the Golgi compartment. This was evident in colocalization immunocytochemical analysis using polyclonal antibodies to PMP22 (Fig. $3 B$ ) and a monoclonal Golgi marker (Fig. $3 A$ ). The majority of the PMP22 immunoreactivity, representative of the steady-state levels of PMP22 in rat SC, was found in the Golgi compartment. A second anti-PMP22 antiserum against the same rat peptide sequence showed low levels of PMP22 distributed more broadly over the cytoplasm, but still with marked concentration of PMP22 in the Golgi (data not shown). These differences may be attributable to the two antibodies recognizing alternative forms or epitopes of PMP22 as noted earlier (Pareek et al., 1993). PMP22 immunoreactivity was never seen in the cell membrane of nonmyelinating SC in culture either before or after permeabilizing the cells.

\section{Biosynthesis of PMP22 in co-cultures of SC and neurons}

To determine whether axonal contact could alter the dynamics of PMP22 production or its localization within SC, we studied PMP22 biosynthesis in DRG-SC co-cultures under conditions that promote myelination. Co-cultures were grown for $7 \mathrm{~d}$, and then myelination was induced by adding ascorbic acid and progesterone to the medium. Three weeks later, the cultures were metabolically labeled for $45 \mathrm{~min}$ and chased for $2 \mathrm{hr}$, and cell extracts were immunoprecipitated with antibodies to PMP22. Aliquots of the samples were also treated with Endo $\mathrm{H}$ before electrophoresis. After this short-term radiolabeling period, most of the PMP22 $(\sim 70 \%)$ synthesized by SC cultured with neurons is Endo $\mathrm{H}$ sensitive (Fig. $4 A$ ). Moreover, after a $2 \mathrm{hr}$ chase only trace amounts of labeled PMP22 remained (Fig. 4A). The rapid turnover of PMP22 in the ER, characteristic of SC alone, is therefore also observed in myelinating $\mathrm{SC}$ in culture. In cultures radiolabeled for $16 \mathrm{hr}, 82 \%$ of the accumulated PMP22 is Endo $\mathrm{H}$ resistant (Fig. 4B, right arrow), a result similar to that obtained in $\mathrm{SC}$ grown in the absence of neurons (Fig. 2). The accumulation of Endo H resistant PMP22 in myelinating SC occurs with about the same time course as it does in $\mathrm{SC}$ alone.

\section{Immunocytochemical localization of PMP22 in co- cultures of SC and neurons}

DRG-SC co-cultures were also examined immunocytochemically to monitor the steady-state distribution of PMP22. In 1-week-old co-cultures grown in medium without ascorbate and progesterone, PMP22 staining was localized to the perinuclear region of SC (Fig. 5B, arrows). This distribution is similar to that of PMP22 in cultures of nonmyelinating SC (Fig. 3B), although the accumulation in the Golgi compartment is not so obvious. Double immunolabeling with the anti-NF antibody (Fig. $5 A$, arrows) showed that the SC are in contact with axons. After an additional 4 weeks in medium containing ascorbate and progesterone (when myelination had occurred), PMP22 was still seen in the SC, but a significant fraction appeared in myelin (Fig. 5D, arrows) along neuro-filament-positive neuronal processes (data not shown). The distribution of PMP22 in myelin (Fig. 5D) was similar to that of P0 (Fig. 5C). Contact with axons therefore promotes the transport of PMP22 from the Golgi compartment to myelin.

\section{Ex vivo labeling of rat sciatic nerve confirms the rapid degradation of newly synthesized PMP22}

To determine how closely the biosynthesis and transport of PMP22 in DRG-SC co-cultures mimicked that in peripheral nerve in vivo, we used explants of 10 -d-old rat sciatic nerves. The explants were metabolically labeled for $30 \mathrm{~min}$ and then chased for different time intervals. Parallel samples were treated with Endo $\mathrm{H}$ to determine the intracellular localization of PMP22. The results showed that most of the newly synthesized PMP22 $(65 \%)$ is sensitive to Endo $\mathrm{H}$ digestion, indicating that the protein is located in the ER and contains high mannose rather than complex carbohydrates (Fig. 6). In these respects the biosynthesis of PMP22 in whole nerve is like that in SC in culture alone or 

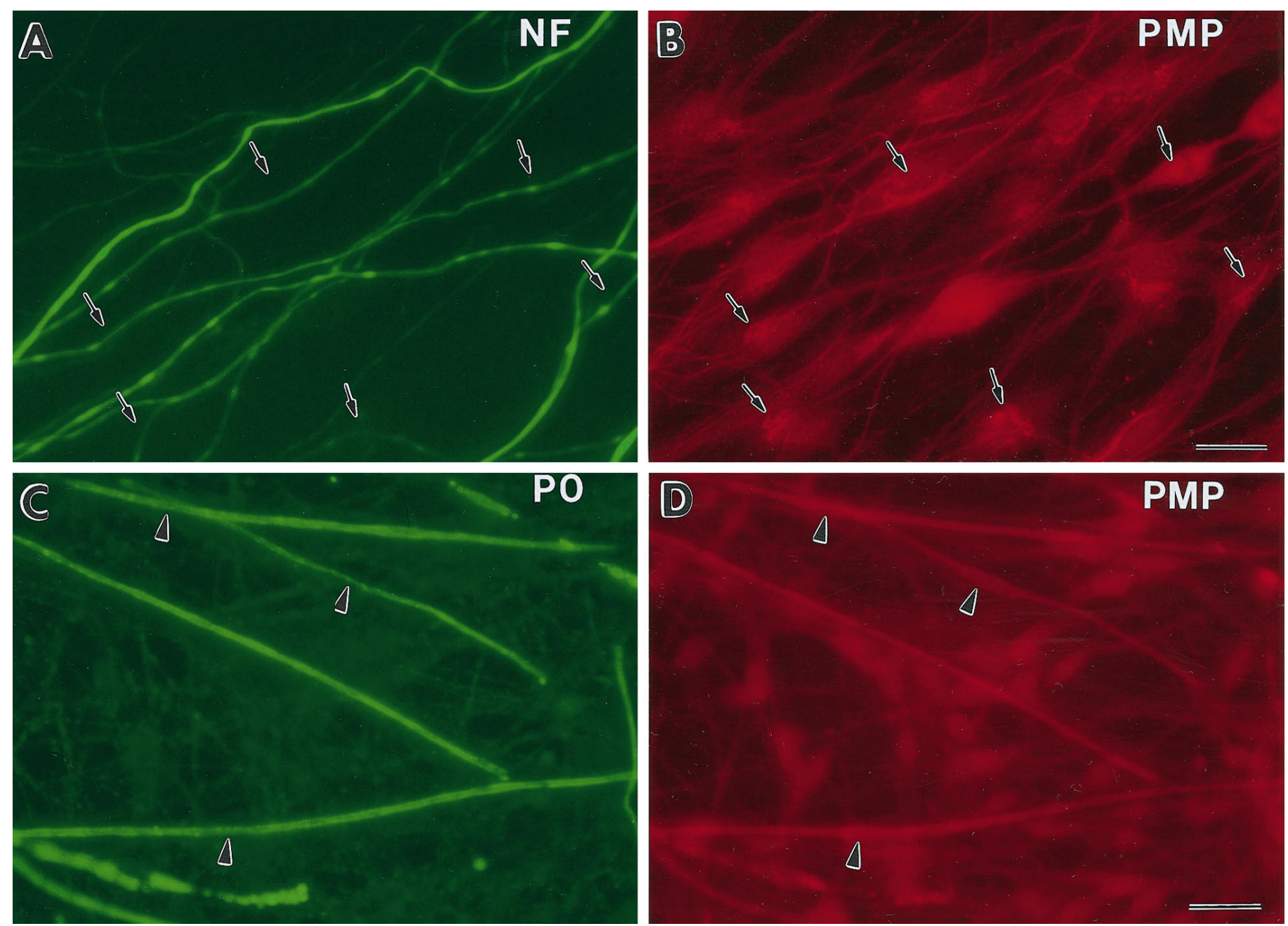

Figure 5. Immunolocalization of PMP22 in short- and long-term myelinating co-cultures. One-week-old SC and neuron co-cultures were double-stained with monoclonal anti-NF $(A)$ and polyclonal PMP22 antiserum $(B)$. Arrows point to SC $(B)$ that are in contact with neuronal processes $(A)$. After 4 weeks in medium that promotes myelination, PMP22 $(D)$ co-localizes with P0 reactive myelin segments $(C)$. Arrows point to the cell bodies of elongated SC $(D)$ with uniform PMP22 staining over the cell membrane. Scale bars: $A, B$ (shown in $B$ ), $22 \mu \mathrm{m} ; C, D$ (shown in $D), 25 \mu \mathrm{m}$.

with neurons. Also, the protein is rapidly degraded (Fig. 6), with a turnover time approximating that observed in SC alone (Fig. $1 A$ ) or DRG-SC co-cultures (Fig. $4 A$ ). This rapid turnover of newly synthesized PMP22 in sciatic nerve occurs in the presence of easily detectable levels of stable PMP22 (by Western analysis) in the nerve myelin throughout the chase period (data not shown). A difference between sciatic nerve explants and SC alone or co-cultures is that the process of conversion of Endo $\mathrm{H}$ sensitive to Endo H resistant PMP22 is much slower in sciatic nerve explants. After a 60 min chase period, $>70 \%$ of total PMP22 becomes Endo $\mathrm{H}$ resistant in $\mathrm{SC}$ and co-cultures whereas in sciatic nerve explants only $40 \%$ of total PMP22 is Endo $\mathrm{H}$ resistant. This difference may be caused by the slow down of sciatic nerve metabolism in our ex vivo conditions.

\section{PMP22 is complex-glycosylated in nonmyelinating and myelinating cells under steady-state conditions}

The data from long-term metabolic labeling suggested that PMP22 becomes Endo $\mathrm{H}$ resistant because it accumulates in the Golgi compartment or myelin. To confirm this, the steady-state PMP22 protein in nonmyelinating SC, 8-week-old myelinating co-cultures, 10-d-old sciatic nerve, and purified myelin from adult nerve was analyzed for sensitivity to Endo H. Under all condi- tions studied PMP22 was largely Endo $\mathrm{H}$ resistant (Fig. 7). Interestingly, low levels of Endo $\mathrm{H}$ sensitive PMP22 were also observed under myelinating conditions. All the Endo $\mathrm{H}$ resistant forms of PMP22 were reduced to the same $18 \mathrm{kDa}$ core protein when treated with PNGase F, an enzyme that removes the single carbohydrate moiety of PMP22 (Fig. 7). The differences in mobility of the glycosylated PMP22 in SC compared with SC under myelinating conditions (Fig. 7) are, therefore, attributable to variations in the composition of the PMP22 carbohydrate side chains. Similar differences in the migration pattern were also seen for newly accumulated PMP22 in SC alone (Fig. 2) and in co-cultures (Fig. 4B).

\section{DISCUSSION}

Metabolic labeling experiments show that most of the newly synthesized PMP22 produced by SC in culture is rapidly turned over and is sensitive to the action of Endo H, suggesting localization to the ER. A small portion of the PMP22 produced during this labeling period, however, becomes complex-glycosylated, as measured by resistance to Endo $\mathrm{H}$. The same profiles were observed for PMP22 biosynthesis in myelinating co-cultures of $\mathrm{SC}$ and neurons and in sciatic nerve explants radiolabeled $e x$ vivo. 
Figure 6. Pulse-chase analysis of ex vivo-labeled sciatic nerve explants. Ten-day-old sciatic nerve segments were metabolically labeled with trans ${ }^{35} \mathrm{~S}$ label for 30 min and chased for 30 and 60 min with cold methionine and cysteine. Nerve homogenates were immunoprecipitated with PMP22 antibodies, and the immunoprecipitates were incubated with $(+)$ or without $(-)$ Endo $\mathrm{H}$ at $4^{\circ} \mathrm{C}$ for $16-18 \mathrm{hr}$. After immunoprecipitation, nerve samples were analyzed by SDS-PAGE and fluorography. Duplicate samples were precipitated using preimmune serum ( first lane in each group). The migration positions of glycosylated $22 \mathrm{kDa}$ PMP22 (top arrow) and the $18 \mathrm{kDa}$ core peptide (bottom arrow) are indicated. Molecular weight markers are shown at the extreme right. Endo $\mathrm{H}$ resistant $(R)$ and sensitive $(S)$ PMP22 are shown as the percentage of total protein at different time intervals.

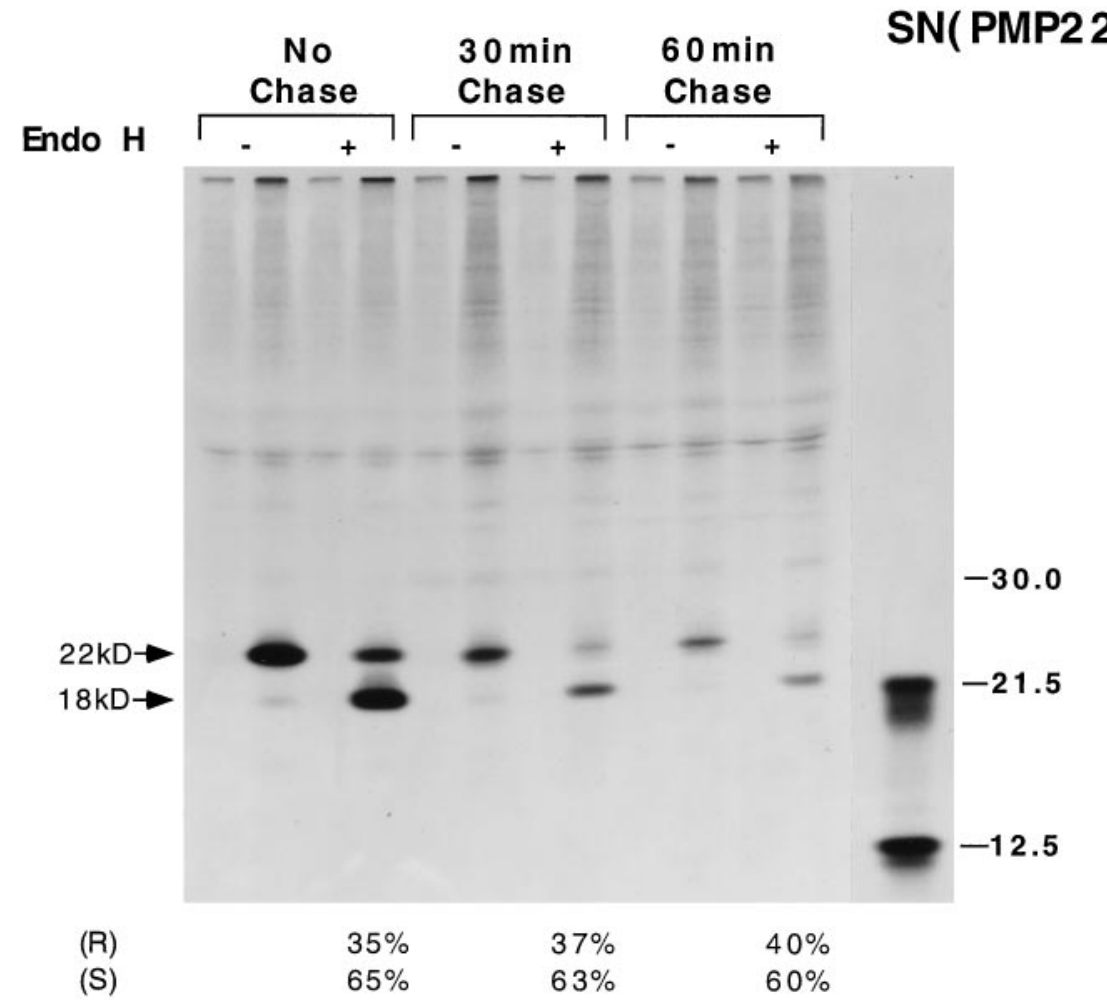

(S)

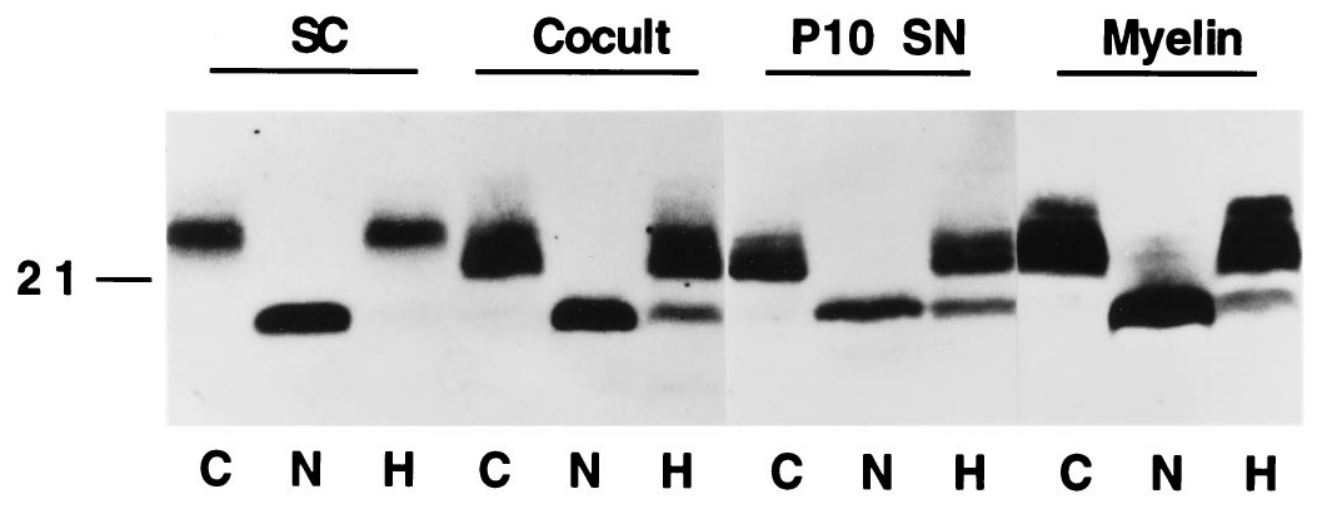

Figure 7. Western blot analysis of PMP22 in in vitro and in vivo samples. PMP22 in nonmyelinating SC $(50 \mu \mathrm{g} /$ lane total protein), 8-week-old myelinating co-cultures $(50 \mu \mathrm{g} /$ lane $), 10-\mathrm{d}$ old sciatic nerve $(10 \mu \mathrm{g} /$ lane $)$, and purified myelin $(10 \mu \mathrm{g} / \mathrm{lane})$ was tested for the presence of high-mannose and complex carbohydrates by PNGase $\mathrm{F}$ $(N)$ and Endo $\mathrm{H}(H)$ treatments as described in Materials and Methods. Control samples incubated without the addition of enzymes are analyzed in lanes $C$. Molecular masses are indicated in kilodaltons.

The process of myelination does not appear to alter significantly the initial steps in PMP22 biosynthesis in SC. Almost 70-80\% of newly synthesized PMP22 is rapidly degraded in the ER in all conditions studied. Long-term metabolic labeling of PMP22 in $\mathrm{SC}$ indicates that the small fraction of Endo H resistant PMP22 seen after short-term labeling increases to become the predominant form of PMP22. Again, the same picture emerges in myelinating SC in culture and in nerve. PMP22 in peripheral nerve myelin is also largely Endo $\mathrm{H}$ resistant. Taken together, these results indicate that stable, predominantly Endo $\mathrm{H}$ resistant forms of PMP22 arise as a result of the processing and accumulation of only a small fraction of the total PMP22 produced by the SC, a process that is not altered significantly during myelination.

What does change during myelination is the intracellular localization of the stable Endo $\mathrm{H}$ resistant PMP22. In SC alone PMP22 accumulates in the Golgi compartment. When axons are present and myelination occurs, PMP22 moves into the myelin membrane. Under identical experimental conditions the dynamics of PMP22 biosynthesis are significantly different from those of $\mathrm{P} 0$, the major SC myelin glycoprotein. In agreement with earlier studies (Poduslo, 1984; Poduslo et al., 1985), we found that most of the $\mathrm{P} 0$ produced by $\mathrm{SC}$ in culture acquires complex glycosylation and Endo $\mathrm{H}$ resistance shortly after its synthesis, and the protein remains stable during the $1 \mathrm{hr}$ chase period. These properties are consistent with the rapid transit of P0 to the SC membrane even in SC cultured alone (L. Notterpek, unpublished data). P0, unlike PMP22, does not require a neuronal signal to become membrane-associated. Furthermore, studies by Brunden and Poduslo (1987) and Brunden et al. (1990a,b) suggest that SC use a post Golgi compartment for the degradation of $\mathrm{P} 0$. In the absence of myelin assembly, in transected nerve and in SC in culture, most of the newly synthesized $\mathrm{P} 0$ is degraded within a 3 hr time period via the lysosomal pathway.

The finding that most of the PMP22 produced by SC is Endo $\mathrm{H}$ sensitive and rapidly turned over suggests that the cell uses some mechanism for degrading PMP22 within the ER. ER degradation of newly synthesized proteins occurs through a nonlysosomal pathway and requires specific signals. For type I transmembrane proteins such as the $\alpha$-chain of the T-cell receptor, charged residues in the transmembrane domain are important determi- 
nants of ER degradation (Bonifacino et al., 1991). In type II transmembrane proteins, including the $\mathrm{H} 2 \mathrm{a}$ subunit of the asialoglycoprotein receptor, sequences in the juxtamembrane region specifically target the protein to the ER degradative pathway (Lederkremer and Lodish, 1991; Wikström and Lodish, 1992; Yuk and Lodish, 1993). PMP22 has four putative transmembrane domains, but none contains charged amino acid residues. Rat PMP22 does have a short amino acid sequence (Asn-Gly-HisArg-Thr) immediately C-terminal to the first membranespanning domain that resembles the sequence that targets the rapid degradation within the $\mathrm{ER}$ of the $\mathrm{H} 2 \mathrm{a}$ subunit of the asialoglycoprotein receptor (Glu-Gly-His-Arg-Gly) (Lederkremer and Lodish, 1991). This sequence may have a similar function with respect to the rapid degradation of PMP22 in the ER.

The significance of accumulation of PMP22 in the Golgi compartment is unknown. It may relate to a yet unidentified role for PMP22 that differs from its function in myelin. PMP22 is a ubiquitous protein (Manfioletti et al., 1990; De Leon et al., 1994; Parmantier et al., 1995), and fibroblasts, among other cells, also produce and rapidly turn over PMP22 (S. Pareek and R. A. Murphy, unpublished data). In SC, retention of PMP22 within the Golgi compartment could be necessary for its targeting to the cell membrane. The "kin recognition" model (Nilsson et al., 1994) suggests that homodimeric proteins may form large oligomers in the Golgi network that prevent their inclusion into transport vesicles. We have observed multimerization of PMP22 ex vivo under nondenaturing conditions (data not shown). PMP22 may also require transient interactions with chaperone proteins or cell-specific PMP22-binding proteins to initiate transfer from the ER and Golgi compartments to the plasma membrane. These chaperones may be absent from nonmyelinating SC.

Although both Endo $\mathrm{H}$ sensitive and resistant PMP22 were reduced to the $18 \mathrm{kDa}$ core protein by PNGase F treatment, some heterogeneity was evident in the migration pattern of the glycosylated $22 \mathrm{kDa}$ protein. These size differences, which probably result from variations in the carbohydrate content of the protein, could be significant in altering the functional properties of the molecule. PMP22 contains the L2/HNK-1 adhesion and recognition carbohydrate epitope (Snipes et al., 1993) that may be important during myelinogenesis and in the maintenance of compact myelin. In nonmyelinating and myelinating SC, steady-state PMP22 contains predominantly complex (Endo H resistant) oligosaccharides; however, in myelinating cells a detectable level of Endo $\mathrm{H}$ sensitive PMP22 is also present. Similar results have been obtained for P0 (Brunden, 1992). In 5-d-old neonatal animals, most of the P0 is complex glycosylated and Endo H resistant, although in the adult, only $60 \%$ of the protein contains complex sugars (Brunden, 1992).

These studies show that most newly synthesized PMP22 is rapidly turned over in the ER. However, a small amount of complex glycosylated PMP22 is accumulated in the Golgi, which is targeted to the membrane under myelinating conditions. $\mathrm{Mu}$ tations in PMP22 disturb the PMP22 trafficking in the SC in unique ways. The effect of the L16P mutation in PMP22 in $T^{J}$ mice does not appear to alter the PMP22 targeting pathway up to its insertion in myelin; however, the myelin that is formed is unstable and undergoes autophagy and/or endocytosis in the endosomal-lysosomal pathway (Notterpek et al., 1997). In contrast, the G160D mutation in $\operatorname{Tr}$ mice prevents the movement of the mutated PMP22 to myelin, and the protein is accumulated in the ER (Naef et al., 1997). It will be of great interest to determine how overexpression or underexpression of PMP22, characteristic of the human peripheral neuropathies, disturbs a system in which much of the normal PMP22 is already degraded in the ER. Animal models for such studies are now available.

\section{REFERENCES}

Adlkofer K, Martini R, Aguzzi A, Zielasek J, Toyka KV, Suter U (1995) Hypermyelination and demyelinating peripheral neuropathy in Pmp22deficient mice. Nat Genet 11:274-280.

Bonifacino JS, Cosson P, Shah N, Klausner RD (1991) Role of potentially charged transmembrane residues in targeting proteins for retention and degradation within the endoplasmic reticulum. EMBO J 10:2783-2793.

Bosse F, Zoidl G, Wilms S, Gillen CP, Kuhn HG, Müller HW (1994) Differential expression of two mRNA species indicates a dual function of peripheral myelin protein PMP22 in cell growth and myelination. J Neurosci Res 37:529-537.

Brockes JP, Fields KL, Raff MC (1979) Studies on cultured rat Schwann cells. I. Establishment of purified populations from cultures of peripheral nerve. Brain Res 165:105-118.

Brunden KR (1992) Age-dependent changes in the oligosaccharide structure of the major myelin glycoprotein, P0. J Neurochem 58:1659-1666.

Brunden KR, Poduslo JF (1987) Lysosomal delivery of the major myelin glycoprotein in the absence of myelin assembly: posttranslational regulation of the level of expression by Schwann cells. J Cell Biol 104:661-669.

Brunden KR, Windebank AJ, Poduslo JF (1990a) Catabolic regulation of the expression of the major myelin glycoprotein by Schwann cells in culture. J Neurochem 54:459-466.

Brunden KR, Windebank AJ, Poduslo JF (1990b) Role of axons in the regulation of P0 biosynthesis by Schwann cells. J Neurosci Res 26:135-143.

Chance PF, Alderson MK, Leppig KA, Lensch MW, Matsunami N, Smith B, Swanson PD, Odelberg SJ, Disteche CM, Bird TD (1993) DNA deletion associated with hereditary neuropathy with liability to pressure palsies. Cell 72:143-151.

Chance PF, Abbas N, Lensch MW, Pentao L, Roa BB, Patel PI, Lupski JR (1994) Two autosomal dominant neuropathies result from reciprocal DNA duplication/deletion of a region on chromosome 17. Hum Mol Genet 3:223-228.

De Leon M, Nahin RL, Mendoza ME, Ruda MA (1994) SR13/PMP-22 expression in rat nervous system, in PC12 cells, and C6 glial cell lines. J Neurosci Res 38:167-181.

DeVries GH, Matthieu J, Beny M, Chicheportiche R, Lazdunski M, Dolivo M (1978) Isolation and partial characterization of rat CNS axolemma enriched fractions. Brain Res 147:339-352.

Einheber S, Milner TA, Giancotti F, Salzer JL (1993) Axonal regulation of Schwann cell integrin expression suggests a role for alpha 6 beta 4 in myelination. J Cell Biol 123:1223-1236.

Kleitman N, Wood PM, Bunge RP (1991) Tissue culture methods for the study of myelination. In: Culturing nerve cells (Banker G, Goslin K, eds), pp 337-378. Cambridge, MA: Massachusetts Institute of Technology.

Koenig HL, Schumacher M, Ferzaz B, Do Thi AN, Ressouches A, Guennoun R, Jung-Testas I, Robel P, Akwa Y, Baulieu E-E (1995) Progesterone synthesis and myelin formation by Schwann cells. Science 268:1500-1503.

Kornfeld R, Kornfeld S (1985) Assembly of asparagine-linked oligosaccharides. Annu Rev Biochem 54:631-664.

Lederkremer GZ, Lodish HF (1991) An alternatively spliced miniexon alters the subcellular fate of the human asialoglycoprotein receptor $\mathrm{H} 2$ subunit. Endoplasmic reticulum retention and degradation or cell surface expression. J Biol Chem 266:1237-1244.

Lemke G, Chao M (1988) Axons regulate Schwann cell expression of the major myelin and NGF receptor genes. Development 102:499-504.

Lowry OH, Rosebrough NJ, Farr AL, Randall RJ (1951) Protein measurement with the Folin phenol reagent. J Biol Chem 193:265-275.

Manfioletti G, Ruaro ME, Del Sal G, Philipson L, Schneider C (1990) A growth arrest-specific (gas) gene codes for a membrane protein. Mol Cell Biol 10:2924-2930.

Martini R, Zielasek J, Toyka KV, Giese KP, Schachner M (1995) Protein zero (P0)-deficient mice show myelin degeneration in peripheral nerves characteristic of inherited human neuropathies. Nat Genet 11:281-286. 
Matsunami N, Smith B, Ballard L, Lensch MW, Robertson M, Albertsen H, Hanemann CO, Muller HW, Bird TD, White R, Chance PF (1992) Peripheral myelin protein-22 gene maps in the duplication in chromosome $17 \mathrm{p} 11.2$ associated with Charcot-Marie-Tooth 1A. Nat Genet 1:176-179.

Naef R, Adlkofer K, Lescher B, Suter U (1997) Aberrant protein trafficking in Trembler suggests a disease mechanism for hereditary human peripheral neuropathies. Mol Cell Neurosci 9:13-25.

Nilsson T, Hoe MH, Slusarewicz P, Rabouille C, Watson R, Hunte F, Watzele G, Berger EG, Warren G (1994) Kin recognition between medial Golgi enzymes in HeLa cells. EMBO J 13:562-574.

Notterpek L, Shooter EM, Snipes GJ (1997) Upregulation of the endosomal-lysosomal pathway in the Trembler-J neuropathy. J Neurosci 17:4190-4200.

Pareek S, Suter U, Snipes GJ, Welcher AA, Shooter EM, Murphy RA (1993) Detection and processing of peripheral myelin protein PMP22 in cultured Schwann cells. J Biol Chem 268:10372-10379.

Parmantier E, Cabon F, Braun C, D’Urso D, Müller HW, Zalc B (1995) Peripheral myelin protein-22 is expressed in rat and mouse brain and spinal cord motoneurons. Eur J Neurosci 7:1080-1088.

Patel PI, Roa BB, Welcher AA, Schoener-Scott R, Trask BJ, Pentao L, Snipes GJ, Garcia CA, Francke U, Shooter EM, Lupski JR, Suter U (1992) The gene for the peripheral myelin protein PMP-22 is a candidate for Charcot-Marie-Tooth disease type 1A. Nat Genet 1:159-165.

Poduslo JF (1984) Regulation of myelination: biosynthesis of the major myelin glycoprotein by Schwann cells in the presence and absence of myelin assembly. J Neurochem 42:493-503.

Poduslo JF, Dyck PJ, Berg CT (1985) Regulation of myelination: Schwann cell transition from a myelin-maintaining state to a quiescent state after permanent nerve transaction. J Neurochem 44:388-400.

Roa BB, Garcia CA, Suter U, Kulpa DA, Wise CA, Mueller J, Welcher AA, Snipes GJ, Shooter EM, Patel PI, Lupski JR (1993a) CharcotMarie-Tooth disease type $1 \mathrm{~A}$. Association with a spontaneous point mutation in the PMP22 gene. N Engl J Med 329:96-101.

Roa BB, Garcia CA, Pentao L, Killian JM, Trask BJ, Suter U, Snipes GJ, Ortiz-Lopez R, Shooter EM, Patel PI, Lupski JR (1993b) Evidence for a recessive PMP22 point mutation in Charcot-Marie-Tooth disease type 1A. Nat Genet 5:189-194.

Roa BB, Dyck PJ, Marks HG, Chance PF, Lupski JR (1993c) DejerineSottas syndrome associated with point mutation in the peripheral myelin protein 22 (PMP22) gene. Nat Genet 5:269-273.

Scherer SS, Chance PF (1995) Myelin genes: getting the dosage right. Nat Genet 11:226-228.

Sereda M, Griffiths I, Pühlhofer A, Stewart H, Rossner MJ, Zimmermann F, Magyar JP, Schneider A, Hund E, Meinck H-M, Suter U, Nave K-A (1996) A transgenic rat model of Charcot-Marie-Tooth disease. Neuron 16:1049-1060.

Snipes GJ, Suter U (1995) Molecular anatomy and genetics of myelin proteins in the peripheral nervous system. J Anat 186:483-494.

Snipes GJ, Suter U, Welcher AA, Shooter EM (1992) Characterization of a novel peripheral nervous system myelin protein (PMP-22/SR13). J Cell Biol 117:225-238.
Snipes GJ, Suter U, Shooter EM (1993) Human peripheral myelin protein-22 carries the L2/HNK-1 carbohydrate adhesion epitope. J Neurochem 61:1961-1964.

Suter U, Welcher AA, Ozcelik T, Snipes GJ, Kosaras B, Francke U, Billings-Gagliardi S, Sidman RL, Shooter EM (1992a) Trembler mouse carries a point mutation in a myelin gene. Nature 356:241-244.

Suter U, Moskow JJ, Welcher AA, Snipes GJ, Kosaras B, Sidman RL, Buchberg AM, Shooter EM (1992b) A leucine-to-proline mutation in the putative first transmembrane domain of the $22 \mathrm{kDa}$ peripheral myelin protein in the trembler-J mouse. Proc Natl Acad Sci USA 89:4382-4386.

Suter U, Welcher AA, Snipes GJ (1993) Progress in the molecular understanding of hereditary peripheral neuropathies reveals new insights into the biology of the peripheral nervous system. Trends Neurosci 16:50-56.

Suter U, Snipes GJ, Schoener-Scott R, Welcher AA, Pareek S, Lupski JR, Murphy RA, Shooter EM, Patel PI (1994) Regulation of tissuespecific expression of alternative peripheral myelin protein-22 (PMP22) gene transcripts by two promoters. J Biol Chem 269:25795-25808.

Timmerman V, Nelis E, Van Hul W, Nieuwenhuijsen BW, Chen KL, Wang S, Ben Othman K, Cullen B, Leach RJ, Hanemann CO, De Jonghe P, Raeymaekers P, van Ommen G-JB, Martin J-J, Müller HW, Vance JM, Fischbeck KH, Van Broeckhoven C (1992) The peripheral myelin protein gene PMP-22 is contained within the Charcot-MarieTooth disease type 1A duplication. Nat Genet 1:171-175.

Towbin H, Staehelin T, Gordon J (1979) Electrophoretic transfer of proteins from polyacrylamide gels to nitrocellulose sheets: procedure and some applications. Proc Natl Acad Sci USA 76:4350-4354.

Valentijn LJ, Bolhuis PA, Zorn I, Hoogendijk JE, van den Bosch N, Hensels GW, Stanton Jr VP, Housman DE, Fischbeck KH, Ross DA, Nicholson GA, Meershoek EJ, Dauwerse HG, van Ommen G-JB, Baas F (1992a) The peripheral myelin gene PMP-22/GAS-3 is duplicated in Charcot-Marie-Tooth disease type 1A. Nat Genet 1:166-170.

Valentijn LJ, Baas F, Wolterman RA, Hoogendijk JE, van den Bosch NHA, Zorn I, Gabreëls-Festen AAWM, deVisser M, Bolhuis PA (1992b) Identical point mutations of PMP-22 in Trembler-J mouse and Charcot-Marie-Tooth disease type 1A. Nat Genet 2:288-291.

Warner LE, Hilz MJ, Appel SH, Killian JM, Kolodny EH, Karpati G, Carpenter S, Watters GV, Wheeler C, Witt D, Bodell A, Nelis E, Van Broeckhoven C, Lupski JR (1996) Clinical phenotypes of different MPZ (P0) mutations may include Charcot-Marie-Tooth type $1 \mathrm{~B}$, Dejerine-Sottas, and congenital hypomyelination. Neuron 17:451-460.

Wikström L, Lodish HF (1992) Endoplasmic reticulum degradation of a subunit of the asialoglycoprotein receptor in vitro. Vesicular transport from endoplasmic reticulum is unnecessary. J Biol Chem 267:5-8.

Yuk MH, Lodish HF (1993) Two pathways for the degradation of the $\mathrm{H} 2$ subunit of the asialoglycoprotein receptor in the endoplasmic reticulum. J Cell Biol 123:1735-1749. 